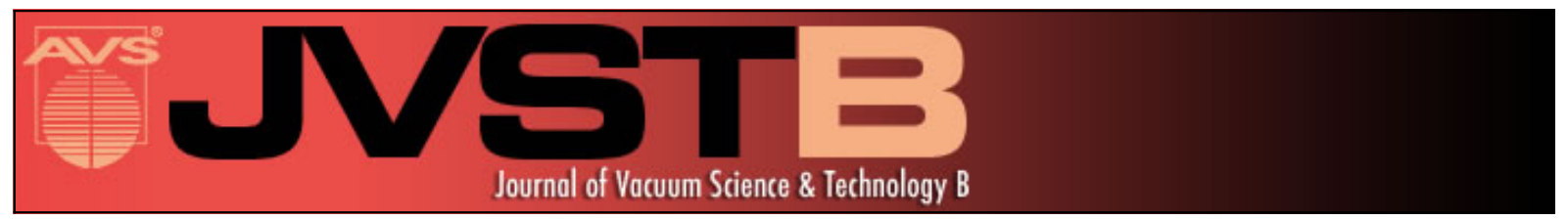

\title{
Novel postetch process to realize high quality photonic crystals in InP
}

N. Shahid, S. Naureen, M. Y. Li, M. Swillo, and S. Anand

Citation: Journal of Vacuum Science \& Technology B 29, 031202 (2011); doi: 10.1116/1.3574760

View online: http://dx.doi.org/10.1116/1.3574760

View Table of Contents: http://scitation.aip.org/content/avs/journal/jvstb/29/3?ver=pdfcov

Published by the AVS: Science \& Technology of Materials, Interfaces, and Processing

\section{Articles you may be interested in}

Gas chopping etching process for InP based nanostructures with high aspect ratios

J. Vac. Sci. Technol. B 30, 060601 (2012); 10.1116/1.4754293

High quality factor two dimensional GaN photonic crystal cavity membranes grown on silicon substrate Appl. Phys. Lett. 100, 071103 (2012); 10.1063/1.3684630

Control of spontaneous emission from InP single quantum dots in GalnP photonic crystal nanocavities Appl. Phys. Lett. 97, 181104 (2010); 10.1063/1.3510469

Edge emitting quantum cascade microlasers on InP with deeply etched one-dimensional photonic crystals Appl. Phys. Lett. 91, 071104 (2007); 10.1063/1.2771054

Fabry-Pérot cavities based on two-dimensional photonic crystals fabricated in InP membranes J. Appl. Phys. 95, 5928 (2004); 10.1063/1.1699495

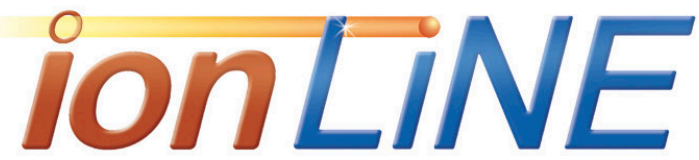

Select $\mathrm{Si}$ ( $\mathrm{Ge}(\mathrm{Au}$ ) and more for Advanced Nanofabrication www.raith.com

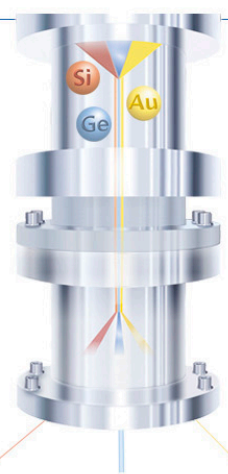

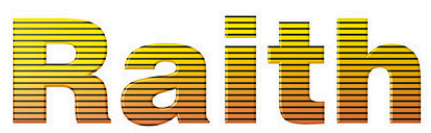




\title{
Novel postetch process to realize high quality photonic crystals in InP
}

\author{
N. Shahid, S. Naureen, M. Y. Li, ${ }^{a)}$ M. Swillo, and S. Anand ${ }^{\text {b) }}$ \\ School of Information and Communication Technology, Royal Institute of Technology, Electrum 229, \\ 16440 Kista, Sweden
}

(Received 21 December 2010; accepted 13 March 2011; published 7 April 2011)

\begin{abstract}
Thermally driven reflow of material during annealing was positively used to obtain near-vertical sidewall profiles for high-aspect-ratio nanostructures in InP fabricated by dry etching. This is very promising for achieving high optical quality in photonic crystal (PhC) components. Nearly cylindrical profiles were obtained for high-aspect-ratio $\mathrm{PhC}$ holes with diameters as small as 200$350 \mathrm{~nm}$. Mini stop bands (MSBs) in line-defect $\mathrm{PhC}$ waveguides were experimentally investigated for both as-etched and reshaped hole geometries, and their spectral characteristics were used to assess the quality of PhC fabrication. The spectral characteristics of the MSB in PhC waveguides with reshaped holes showed significant improvement in performance with a transmission dip as deep as $35 \mathrm{~dB}$ with sharp edges dropping in intensity more than $30 \mathrm{~dB}$ for $\sim 4 \mathrm{~nm}$ of wavelength change. These results show potential for using high extinction drop-filters in InP-based monolithic photonic integrated circuit applications. Finally, it is proposed that other nanostructure geometries may also benefit from this reshaping process. () 2011 American Vacuum Society.
\end{abstract}

[DOI: $10.1116 / 1.3574760]$

\section{INTRODUCTION}

In recent years there has been significant research on twodimensional (2D) photonic crystals (PhCs), owing to their interesting optical properties and their potential applications in optical communications. InP-based PhCs have attracted much attention because both active and passive components can be realized, and also they are compatible for integration with conventional photonic components on InP substrate. Although several $\mathrm{PhC}$ devices such as filters, lasers, and waveguides have been demonstrated, it is commonly recognized that fabrication of $\mathrm{PhCs}$ with higher optical quality is essential for low-loss components.

$\mathrm{PhC}$ waveguides have been investigated extensively for their unique slow light ${ }^{1-3}$ and dispersion control $^{4-6}$ properties. An interesting property of these waveguides is the socalled mini stop band (MSB), or mode-gap, which originates from energy transfer between forward and backward propagating modes. ${ }^{7,8}$ This effect has been investigated not only from a fundamental physics point of view, but also for device applications such as pulse compression, ${ }^{9}$ coarse wavelength selection, ${ }^{10,11}$ optical filters, ${ }^{12}$ selective mirroring in $\mathrm{PhC}$ lasers, ${ }^{13}$ and fluid sensors. ${ }^{14}$ However, the optical characteristics of the MSBs are closely linked to the optical loss, thus requiring significant improvement in the quality of fabricated PhCs.

Because the vertical light confinement is weak for PhCs in low vertical index contrast structures (e.g., InP/GaInAsP/ $\mathrm{InP}$ ), $\mathrm{PhC}$ holes (typically $200-300 \mathrm{~nm}$ in diameter) have to be etched down to at least $2 \mu \mathrm{m}$ to ensure good overlap between the modal profile and the PhC holes. ${ }^{15}$ In addition,

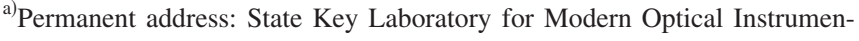
tation, Zhejiang University, Hangzhou 310027, China.

${ }^{b)}$ Author to whom correspondence should be addressed; electronic mail: anand@kth.se
}

the sidewalls of the etched holes must be as vertical as possible for low optical loss. ${ }^{16}$ Significant advances have been made in this regard. For example, etch depths up to 3-5 $\mu \mathrm{m}$ have been obtained by chemically assisted ion beam etching ${ }^{15,17}$ (CAIBE) or by inductively coupled plasma reactive ion etching ${ }^{18-20}$ using halogen chemistry. However, irrespective of technique and chemistry, the etched PhCs' (circular) holes are invariably either conical or "cylindroconical," with nearly vertical sections on the order of 1-2 $\mu \mathrm{m}$ (with the total depth being typically $4 \mu \mathrm{m}$ ). Prolonged exposure to ion-bombardment during etching increases sidewall damage ${ }^{20,21}$ and degrades the material properties, which is undesirable, especially for active devices. These observations suggest that these etching processes have fundamental limitations and that a postetch process step may be required to achieve vertical sidewalls. It has been shown that material reflow during the overgrowth step in the fabrication of distributed feedback (DFB) lasers reduces the sharpness and aspect ratios of the gratings. ${ }^{22-24}$ Efforts are made to suppress this phenomenon, ${ }^{22-24}$ but it can be advantageously applied to reshape etched nanostructures such as $\mathrm{PhC}$ holes and trenches (slots). Such an annealing process may also be beneficial in reducing the etch-induced damage.

In this study, we demonstrated that as-etched high-aspect nanostructures [one-dimensional (1D) and 2D PhCs] in InPbased materials can be significantly improved in terms of sidewall verticality using material reflow by annealing. The spectral characteristics of MSBs in line-defect (three row missing) multimode $\mathrm{PhC}$ waveguides are used as quality indicators of $\mathrm{PhC}$ fabrication. The measured spectral characteristics of MSBs in the $\mathrm{PhC}$ waveguides with reshaped holes were significantly improved compared to those in as-etched $\mathrm{PhC}$ waveguides. MSBs with transmission extinction ratios as high as $35 \mathrm{~dB}$ and sharp edges where intensities dropped more than $30 \mathrm{~dB}$ over less than a $4 \mathrm{~nm}$ wavelength change 

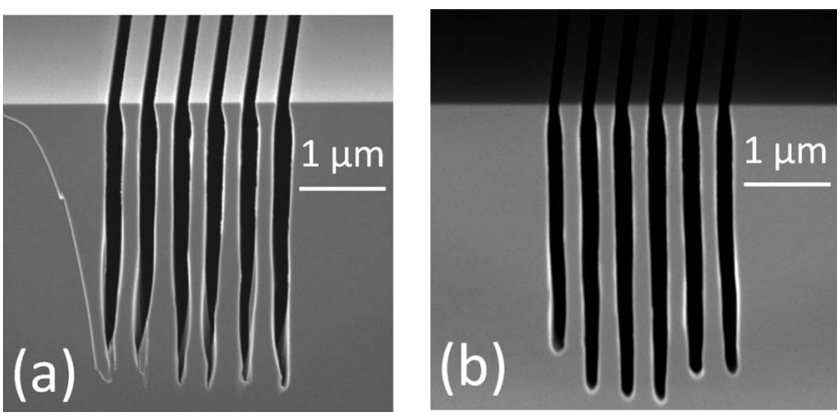

FIG. 1. Cross-sectional scanning electron microscopy (SEM) images of (a) 1D-slot as-etched and (b) reshaped 1D-slot after annealing.

were demonstrated for 50- $\mu \mathrm{m}$-long waveguides. Reshaped $\mathrm{PhCs}$ show promise for achieving high-optical-quality (lowloss) photonic components.

\section{EXPERIMENTAL METHODS}

The InP/InGaAsP/InP low index contrast slab was grown by metal organic vapor phase epitaxy on $\mathrm{InP}$ substrate. The InP cap and GaInAsP core lattice matched to $\operatorname{InP}\left(\lambda_{\text {gap }}\right.$ $=1.22 \mu \mathrm{m})$ were 200 and $420 \mathrm{~nm}$ thick, respectively. For preliminary investigation of annealing effects on the profiles (shape and roughness) of high-aspect-ratio nanostructures both $1 \mathrm{D}$ and $2 \mathrm{D} \mathrm{PhC}$ test structures were fabricated. 1D air slots of $100 \mu \mathrm{m}$ length were made with widths in the 150 $350 \mathrm{~nm}$ range and pitches in the range $400-600 \mathrm{~nm}$. These 1D test structures are relevant to on-chip distributed Bragg reflectors (DBRs) at optical communication wavelengths. The 2D PhC test structures had hole-diameters in the range of 200-350 nm. The PhC waveguides oriented in the $\Gamma-K$ direction with three missing rows (here referred to as W3 $\mathrm{PhC}$ waveguides) in a triangular lattice of air-holes have a period of $420 \mathrm{~nm}$ and are 120 rows long. Hereafter, we will use the term $\mathrm{PhC}$ waveguide to mean a $\mathrm{W} 3 \mathrm{PhC}$ waveguide. The $\mathrm{PhC}$ waveguide section was inserted in between two $1.2-\mu \mathrm{m}$-wide access-ridge waveguides, each approximately $0.75 \mathrm{~mm}$ long. The PhC patterns were made by electron beam lithography using ZEP520 as the resist. The patterns were then transferred in to a 260 -nm-thick $\mathrm{SiO}_{2}$ mask using $\mathrm{CHF}_{3}$-based reactive ion etching. Subsequently, the $\mathrm{PhCs}$ were etched using $\mathrm{Ar} / \mathrm{Cl}_{2} \mathrm{CAIBE}$. Details of the etching process and process conditions are given in Ref. 15. After etching, the test structures and $\mathrm{PhC}$ waveguides were annealed at $630{ }^{\circ} \mathrm{C}$ under $\mathrm{PH}_{3}$ for 2 min-typical conditions for regrowth. The main purpose of this annealing step was to reshape the etched $\mathrm{PhC}$ holes by reflow of material around the exposed surfaces. The $\mathrm{SiO}_{2}$ mask is retained during this step to ensure that any eventual material reflow affects only the exposed sidewalls.

\section{RESULTS AND DISCUSSION}

Figure 1(a) shows the cross-section of an etched 1D-slot structure (representative). The slot width is $150 \mathrm{~nm}$ and the period is $400 \mathrm{~nm}$. As seen from the figure, the as-etched profiles are irregular (e.g., bending) and are also strongly
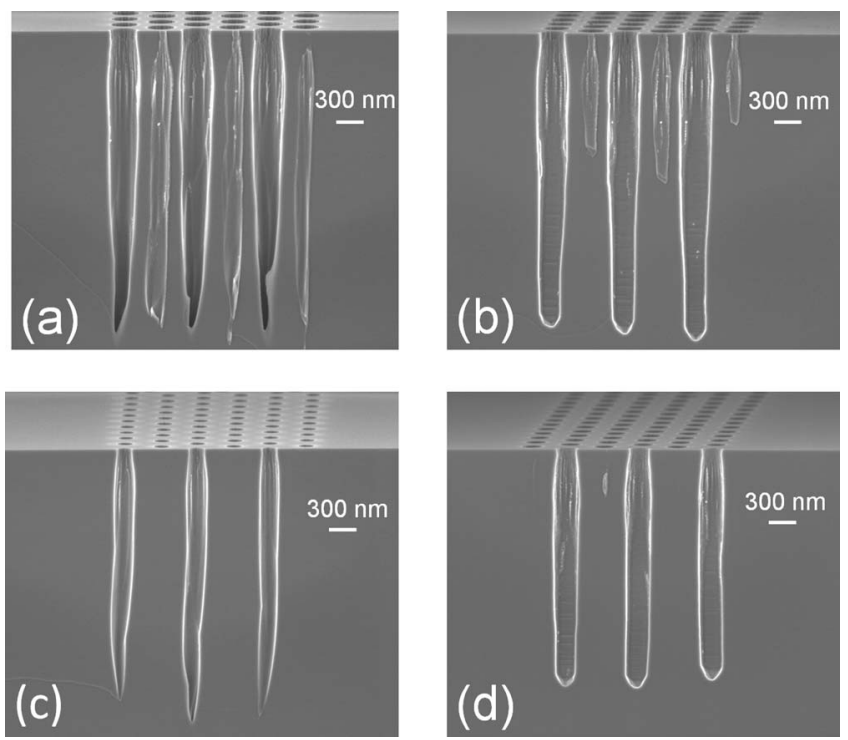

FIG. 2. Cross-sectional SEM images of [(a) and (c)] PhC as-etched and [(b) and $(\mathrm{d})]$ reshaped $\mathrm{PhC}$ after annealing.

tapered at the bottom. The other test patterns show similar profiles. Figure 1(b) shows the cross-section of an etched slot structure after annealing. Figure 1(b) shows the cross-section of an etched slot structure after annealing. The structures shown in Figs. 1(a) and 1(b) have the same geometrical parameters (slot width and pitch) and were etched together. It is evident from Fig. 1(b) that annealing clearly improved the profiles in terms of irregularities and sidewall verticality. We attribute this change in profiles to reflow of material (i.e., redistribution of material) occurring on the exposed (etched) surfaces. These results are of interest primarily for on-chip laser DBR-mirrors for which mirror loss due to tapering can be reduced. Figure 2 shows the results obtained for 2D PhCs. Here, the comparison is made for $2 \mathrm{D} \mathrm{PhCs}$ having the same geometrical parameters (hole-diameter and period), and those were etched together. The as-etched hole profiles [Figs. 2(a) and 2(c)] show tapered bottom profiles and irregularities (bending) typical of deeply etched $\mathrm{PhCs}$ in InP. The upper part of the etched structure is reasonably vertical as typically observed. ${ }^{15}$ In striking contrast, as is evident in Figs. 2(b) and 2(d), material reflow not only removes (smoothens) any irregularities, but also results in nearly cylindrical hole profiles. Thus, imperfections in $\mathrm{PhC}$ due to variations in feature size and shape introduced at the pattern transfer step can be effectively reduced using material reflow. The observations clearly demonstrate that material reflow can be used positively to fabricate $1 \mathrm{D}$ and $2 \mathrm{D}$ nanostructures with vertical sidewalls.

Inspection of the slot (Fig. 1) and hole (Fig. 2) profiles suggests that reflow/redistribution of the material depends on the sidewall angle. The profiles in the upper portion where they are nearly vertical or slightly underetched are practically unaltered by annealing. This suggests that redistribution of the materials in those regions is not sufficient to smoothen out the sidewall roughness. However, the microscopic origin of the roughness in terms of the surface distribution of the 


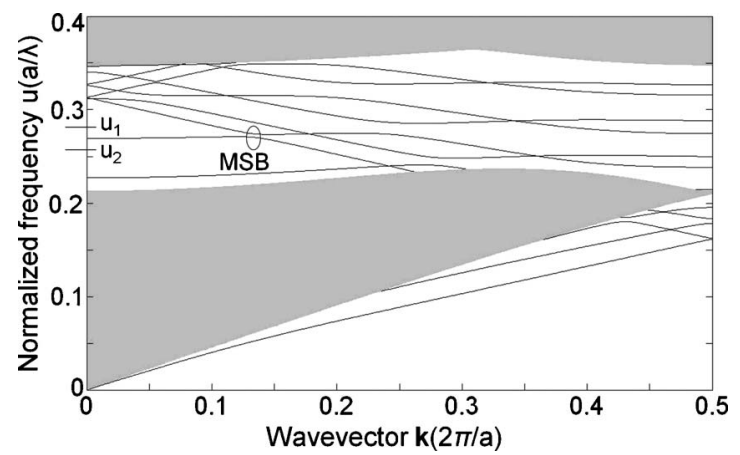

FIG. 3. Dispersion diagram of the PhC waveguide showing the region of interest where $u_{1}=0.275$ and $u_{2}=0.261$.

elements (e.g., In, P, Ga, and As) may also play a role. It is recognized that material reflow depends on the annealing temperature and duration, on the as-etched profile, and on the material composition at the surface. A detailed study of the effect of these parameters on the resulting hole shape is beyond the scope of this article. Our main emphasis is to demonstrate that such a postprocess step could significantly improve the quality of the photonic devices. Specifically, because our etch process is better optimized for air-hole scheme, the impact of the reshaping process on $\mathrm{PhC}$ devices is demonstrated using $\mathrm{W} 3 \mathrm{PhC}$ waveguides as an example. Spectral characteristics of MSBs are used to qualify $\mathrm{PhC}$ fabrication. Below, we discuss the optical measurements of the $\mathrm{PhC}$ waveguides.

The $\mathrm{PhC}$ waveguides were characterized by the end-fire technique. An amplified spontaneous emission source with a spectral range of 1530-1610 nm was used as the light source and was coupled into the cleaved facet of the input accessridge waveguide through a focusing gradient index lens. The output light was collected by a microscope objective and split into two beams: one to an infrared camera for alignment and imaging and the other to an optical spectrum analyzer through a single mode fiber to measure the transmission spectra. Polarizers were used at both input and output of the sample to ensure that only transverse electric modes were excited in access waveguides. Conventional ridge waveguides were fabricated together with the $\mathrm{PhC}$ waveguides to serve as references for normalizing the transmission spectra.

Figure 3 shows the dispersion diagram calculated by the plane-wave expansion (PWE) method for the W3 PhC waveguide. The PWE calculations were made for an effective index of 3.24 and an air-fill factor of $42 \%{ }^{8}$ Refractive indices of 3.17 and 3.35 were used for InP and GaInAsP, respectively. As seen in Fig. 3, the mode-gap or MSB due to coupling between the first and fifth order modes ${ }^{7,8}$ occurs at approximately $u=0.27$, where $u$ is the normalized frequency $(u=a / \lambda)$. Given the period $a=420 \mathrm{~nm}$, this value of $u$ $=0.27$ corresponds to the center wavelength of $\sim 1556 \mathrm{~nm}$. As a result of this mode-gap the transmission spectrum is expected to exhibit a dip in the corresponding wavelength region. The transmission spectrum for the $\mathrm{PhC}$ waveguide

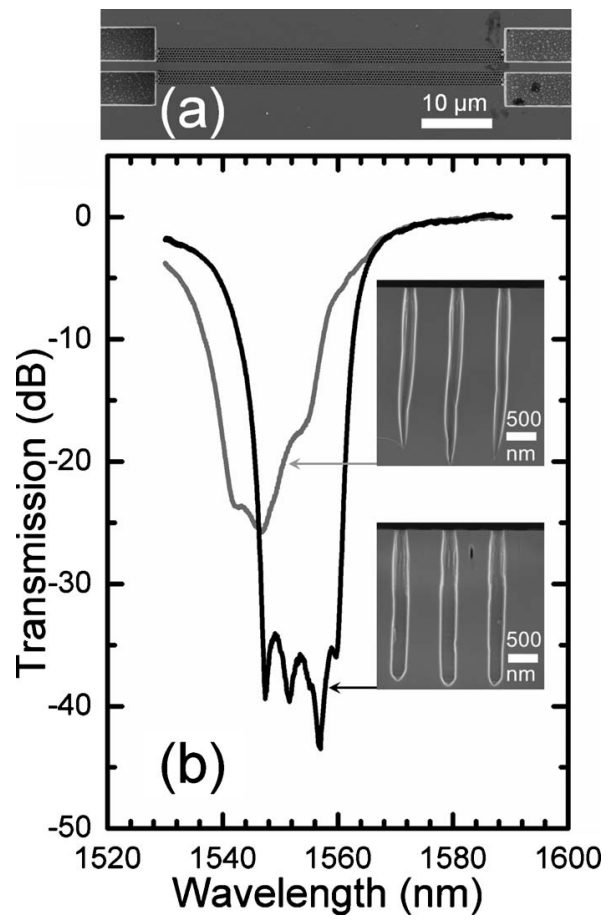

FIG. 4. (a) SEM top view of a fabricated PhC waveguide; part of the accessridge waveguides is also visible. (b) Measured transmission spectra (normalized) comparing as-etched and annealed (reshaped) $\mathrm{PhC}$ waveguides.

was simulated using 2D finite-difference-time-domain (FDTD) and shows a MSB-dip in the wavelength region predicted by PWE calculations.

Figure 4(a) shows the top view of a fabricated $\mathrm{PhC}$ waveguide; parts of the access-ridge waveguides are also visible. Figure 4(b) shows the measured transmission spectra of two $\mathrm{PhC}$ waveguides of $50 \mu \mathrm{m}$ length: one as-etched and the other with reshaped holes. In both samples, the characteristic dip in transmission due to the MSB effect is evident, and the wavelength range where it occurs agrees well with PWE calculations (Fig. 3). However, the difference in the samples' MSB spectral characteristics is striking. For the sample with reshaped holes, the measured dip due to the MSB (hereafter referred to as MSB-dip) is as deep as $35 \mathrm{~dB}$. The transmission bandwidth for the MSB was $12 \mathrm{~nm}$. The transmission at the edges dropped sharply-more than $30 \mathrm{~dB}$ for $\sim 4 \mathrm{~nm}$ change of wavelength, approximately $\sim 4$ times steeper compared to the previous best result. ${ }^{8}$ The shape and depth of the MSB-dip for the as-etched sample [Fig. 4(b)] are comparatively inferior. These results clearly demonstrate that the reshaping procedure significantly improves the optical quality of PhC waveguides. In a previous work, ${ }^{8}$ 2D FDTD simulations including an effective loss parameter showed that as the loss increased, the MSB-dip became shallower. Based on those results, reduced extrinsic optical loss should result in steeper MSB-dips, as was observed for the samples with reshaped holes. The slope of transmission at the edges of MSBs was also comparable to that observed for 2D FDTD simulations. To account for the exact geometry of the holes, 
a more rigorous analysis of the experimental data would need to be conducted using 3D simulations, but this is outside the scope of this study.

The $\mathrm{PhC}$ waveguides with reshaped profiles may be used as monolithically integrated passive filters in applications requiring very high extinction/rejection ratios. An interesting application example would be for DFB lasers where they can potentially be used as DBR-like mirrors for the light that propagates through the line-defect waveguide. The performance of the proposed waveguides as filters (stop-band extinction) may be limited by the presence of the third order mode. The third order mode can also be excited in the $\mathrm{PhC}$ waveguide, which can limit the observed MSB depth. Davano et al. ${ }^{12}$ described broadband filters for monolithic photonic integrated circuits using the MSB effect. The demonstrated transmission extinction ratio for these filters is equal to $20 \mathrm{~dB}$. It is worth noting that in our annealed $\mathrm{PhC}$ waveguides the obtained transmission extinction ratio was as large as $35-40 \mathrm{~dB}$. The group velocity can be reduced because of dispersion arising from mode coupling between the fundamental and higher order modes at mode singularities. ${ }^{3}$ A low group velocity is a promising solution for enhancement of linear and nonlinear optical effects, buffering, and time-domain processing of optical signals. However, the use of slow light in such structures requires further investigation, specifically taking into consideration the optical loss and multimode nature of the waveguide. Sharp transmission edges of MSB can be expected to be very sensitive to changes in the material refractive index and/or to substances filled in the air-holes of PhCs. This could be of potential interest for sensing, tuning, and modulation applications and will be the subject matter of our future investigations.

\section{CONCLUSIONS}

In conclusion, a postetch annealing step resulting in reflow of material around the exposed surfaces of the etched PhC holes significantly improved the sidewall verticality. Annealing can effectively reduce imperfections in $\mathrm{PhCs}$ which are caused by variations in feature size and shape introduced at the pattern transfer steps. The MSBs for $\mathrm{PhC}$ waveguides fabricated using a reshaping process exhibited excellent spectral characteristics. The transmission extinction ratios of more than $35 \mathrm{~dB}$ achieved for $\sim 12 \mathrm{~nm}$ bandwidth in a simple waveguide transmission geometry may potentially be attractive for use in tunable band filters and on-chip mirrors. The sharp MSB edges realized in this work may apply to optical sensing, tuning, and modulation. Here, we have demonstrated the efficacy of the reshaping process using material reflow by annealing in the context of MSB in
PhC waveguides and InP-based materials, and we also propose that this process will be beneficial to other $\mathrm{PhC}$ devices, nanostructure geometries, and materials.

\section{ACKNOWLEDGMENTS}

This work was supported by the Swedish Research Council (VR) and the Swedish Strategic Research Foundation (SSF).

${ }^{1}$ T. Baba, Nat. Photonics 2, 465 (2008).

${ }^{2}$ M. L. Povinelli, S. G. Johnson, and J. D. Joannopoulos, Opt. Express 13, 7145 (2005).

${ }^{3}$ E. Schwoob, H. Benisty, C. Weisbush, C. Cuisin, E. Derouin, O. Drisse, G. H. Duan, L. Legouézigou, O. Legouézigou, and F. Pommereau, Opt. Express 12, 1569 (2004).

${ }^{4}$ M. Notomi, K. Yamada, A. Shinya, J. Takahashi, C. Takahashi, and I. Yokohama, Phys. Rev. Lett. 87, 253902 (2001).

${ }^{5}$ A. Säynätjoki, M. Mulot, J. Ahopelto, and H. Lipsanen, Opt. Express 15, 8323 (2007).

${ }^{6}$ A. Di Falco, L. O'Faolain, and T. F. Krauss, Appl. Phys. Lett. 92, 083501 (2008).

${ }^{7}$ S. Olivier, M. Rattier, H. Benisty, C. J. M. Smith, R. M. De La Rue, T. F. Krauss, U. Oesterle, R. Houdré, and C. Weisbuch, Phys. Rev. B 63, 113311 (2001).

${ }^{8}$ M. Mulot, S. Anand, M. Swillo, M. Qiu, B. Jaskorzynska, and A. Talneau, J. Vac. Sci. Technol. B 21, 900 (2003).

${ }^{9}$ T. Cao, M. J. Cryan, P. S. Ivanov, D. Ho, B. Ren, I. J. Craddock, J. M. Rorison, and C. J. Railton, J. Opt. Soc. Am. B 24, 1575 (2007).

${ }^{10}$ E. Viasnoff-Schwoob, C. Weisbuch, H. Benisty, C. Cuisin, E. Derouin, O. Drisse, G. H. Duan, L. Legouézigou, S. Golka, H. Heidrich, H. J. Hensel, and K. Janiak, Appl. Phys. Lett. 86, 101107 (2005).

${ }^{11}$ H. Benisty, C. Cambournac, F. Van Laere, and D. Van Thourhout, J. Lightwave Technol. 28, 1201 (2010).

${ }^{12}$ M. Davano, A. Xing, J. W. Raring, E. L. Hu, and D. J. Blumenthal, IEEE J. Sel. Top. Quantum Electron. 12, 1164 (2006).

${ }^{13}$ S. A. Moore, L. O'Faolain, T. P. White, and T. F. Krauss, Opt. Express 16, 1365 (2008).

${ }^{14}$ L. Cao, Y. D. Huang, X. Y. Mao, F. Li, W. Zhang, and J. D. Peng, Chin. Phys. Lett. 25, 2101 (2008).

${ }^{15}$ A. Berrier, M. Mulot, A. Talneau, R. Ferrini, R. Houdré, and S. Anand, J. Vac. Sci. Technol. B 25, 1 (2007).

${ }^{16}$ R. Ferrini, B. Lombardet, B. Wild, R. Houdré, and G. H. Duan, Appl. Phys. Lett. 82, 1009 (2003).

${ }^{17}$ M. V. Kotlyar, L. O’Faolain, R. Wilson, and T. F. Krauss, J. Vac. Sci. Technol. B 22, 1788 (2004).

${ }^{18}$ F. Pommereau, L. Legouézigou, S. Hubert, S. Sainson, J.-P. Chandouineau, S. Fabre, G. H. Duan, B. Lombardet, R. Ferrini, and R. Houdré, J. Appl. Phys. 95, 2242 (2004).

${ }^{19}$ C. F. Carlström, R. van der Heijden, F. Karouta, R. W. van der Heijden, H. W. M. Salemink, and E. van der Drift, J. Vac. Sci. Technol. B 24, L6 (2006).

${ }^{20}$ J. F. Holzman, P. Strasser, R. Wüest, F. Robin, D. Erni, and H. Jäckel, Nanotechnology 16, 949 (2005).

${ }^{21}$ A. Berrier, Y. Shi, J. Seigert, S. Marcinkevicius, S. He, and S. Anand, J. Vac. Sci. Technol. B 27, 1969 (2009).

${ }^{22}$ Z. L. Liau and J. N. Walpole, Appl. Phys. Lett. 40, 568 (1982).

${ }^{23}$ T. Inoue, S. Nakajima, Y. Luo, T. Oki, H. Iwaoka, Y. Nakano, and K. Tada, Jpn. J. Appl. Phys., Part 2 30, L1808 (1991).

${ }^{24}$ A. J. Taylor, A. S. Bridges, J. Hardwick, H. Lage, R. H. Moss, and W. S. Ring, J. Electron. Mater. 26, 1131 (1997). 